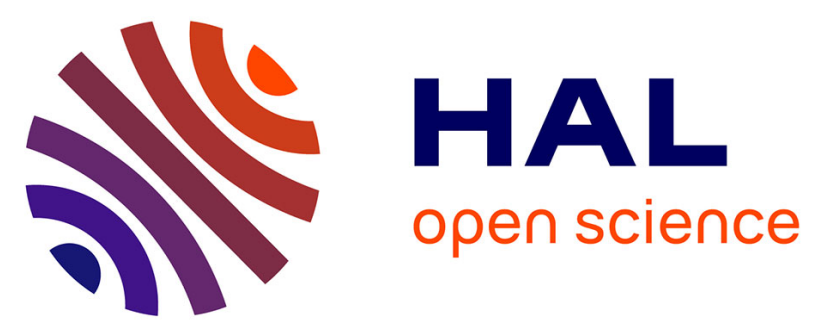

\title{
Understanding the influence of operating parameters throughin silicooptimization of energy consumption of submerged membrane bioreactor for urban wastewater treatment
}

Yusmel González Hernández, Ulises Javier Jáuregui Haza, Claire Albasi, Marion Alliet

\section{To cite this version:}

Yusmel González Hernández, Ulises Javier Jáuregui Haza, Claire Albasi, Marion Alliet. Understanding the influence of operating parameters throughin silicooptimization of energy consumption of submerged membrane bioreactor for urban wastewater treatment. Desalination and Water Treatment, 2015, pp. 1-13. 10.1080/19443994.2015.1081631 . hal-01205310

\author{
HAL Id: hal-01205310 \\ https://hal.science/hal-01205310
}

Submitted on 25 Sep 2015

HAL is a multi-disciplinary open access archive for the deposit and dissemination of scientific research documents, whether they are published or not. The documents may come from teaching and research institutions in France or abroad, or from public or private research centers.
L'archive ouverte pluridisciplinaire HAL, est destinée au dépôt et à la diffusion de documents scientifiques de niveau recherche, publiés ou non, émanant des établissements d'enseignement et de recherche français ou étrangers, des laboratoires publics ou privés. 


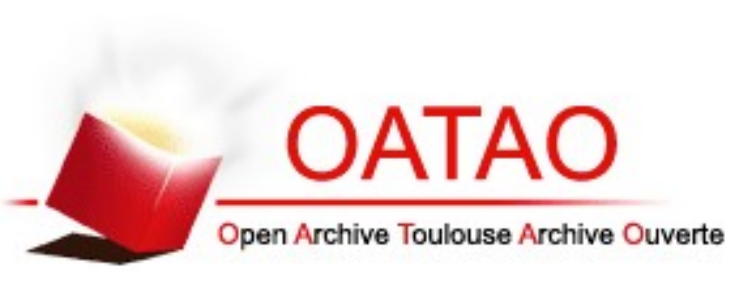

\section{Open Archive TOULOUSE Archive Ouverte (OATAO)}

OATAO is an open access repository that collects the work of Toulouse researchers and makes it freely available over the web where possible.

This is an author-deposited version published in : http://oatao.univ-toulouse.fr/ Eprints ID : 14282

To link to this article : DOI:10.1080/19443994.2015.1081631

URL:http://dx.doi.org/10.1080/19443994.2015.1081631

To cite this version : González Hernández, Yusmel and Jáuregui Haza, Ulises Javier and Albasi, Claire and Alliet, Marion

Understanding the influence of operating parameters throughin silicooptimization of energy consumption of submerged membrane bioreactor for urban wastewater treatment. (2015) Desalination and Water Treatment. pp. 1-13. ISSN 1944-3994

Any correspondance concerning this service should be sent to the repository administrator: staff-oatao@listes-diff.inp-toulouse.fr 


\title{
Understanding the influence of operating parameters through in silico optimization of energy consumption of submerged membrane bioreactor for urban wastewater treatment
}

\author{
Yusmel González Hernández ${ }^{a, b, c}$, Ulises Javier Jáuregui Haza ${ }^{a}$, Claire Albasi ${ }^{b, c}$, \\ Marion Alliet ${ }^{\mathrm{b}, \mathrm{c}, *}$ \\ ${ }^{a}$ Facultad de Medio Ambiente, Instituto Superior de Tecnologías y Ciencias Aplicadas, Avenida Salvador Allende esquina Luaces, \\ La Habana, Cuba, Tel. +5372711836; emails: yusmel@instec.cu (Y. González Hernández), ulises.jauregui@infomed.sld.cu \\ (U.J. Jáuregui Haza) \\ ${ }^{b}$ Université de Toulouse, INPT, UPS, LGC, 4, Allée Emile Monso, F-31432 Toulouse, France, email: claire.albasi@ensiacet.fr \\ (C. Albasi), Tel. +3305343236 30; Fax: + 3305343237 00; email: marion.alliet@ensiacet.fr (M. Alliet) \\ ${ }^{c}$ Laboratoire de Génie Chimique, CNRS, F-31030 Toulouse, France
}

\begin{abstract}
Membrane bioreactor technology has become relatively widespread as an advanced treatment for both industrial and municipal wastewaters. The main problem of these installations is that they do not operate at the maximum of their potential, mainly because of membrane fouling. Experimental research with this kind of installation requires resources and is time consuming. The use of a computer simulator, as in the present work, allows the fouling behaviour in a bench-scale submerged membrane bioreactor to be investigated over a wide range of operating parameters: average specific aeration intensity $\left(0.041-0.277 \mathrm{~L} \mathrm{~m}^{-2} \mathrm{~s}^{-1}\right)$, filtration flux $\left(0.032-0.160 \mathrm{~m}^{3} \mathrm{~m}^{-2} \mathrm{~d}^{-1}\right)$ and filtration and coarse bubble aeration cycles (filtration and aeration times: $60-1080 \mathrm{~s}$, with/without ratio: 0.33/10). A quadratic optimization method applied to the energy consumption (EC) was first carried out: minimum values of 0.27 and $0.32 \mathrm{~kW} \mathrm{~h} \mathrm{~m}^{-3}$ were obtained for EC in the sequential and non-sequential operating modes, respectively. Using the optimal operating conditions and the most influent parameters found in the first part, the second part details their influence on both membrane fouling and EC for each operating mode. The mean filtration flux and the mean aeration intensity have opposite effects on fouling and EC, which implies that a more global, economic optimization, including chemical cleaning, is needed. The detailed study of filtration and coarse bubble aeration cycles showed that they had little influence for a with/without ratio superior to 1 . Using the quadratic optimization method with in silico experiments gave reliable first approximation results.
\end{abstract}

Keywords: Quadratic optimization; Submerged membrane bioreactor; Urban wastewaters simulator

*Corresponding author. 


\section{Introduction}

Membrane bioreactor (MBR) technology has become relatively widespread as advanced treatment for both industrial and municipal wastewaters, especially in areas prone to water scarcity $[1,2]$. In the last two decades, MBR technology has grown exponentially because of the advantages it offers over conventional treatment processes, such as smaller footprint, advantageous effluent quality and better process control [3]. However, MBRs also have some disadvantages that limit their application, in particular, membrane fouling [4-8]. Membrane fouling can be defined as the undesirable deposition and accumulation of micro-organisms, colloids, solutes and cell debris within and/or on membranes $[5,9]$. Shear, in the form of vigorous aeration, is used to control fouling in MBR systems [10]. Nevertheless, membrane aeration is the major item in operating costs [6]. The energy demand of municipal wastewater treatment using MBRs is reported to be 2-4 times higher than that of the conventional activated sludge process [11], with a total EC in the range of 0.14-8 $\mathrm{kW} \mathrm{h} \mathrm{m}{ }^{-3}[7,12-14]$. The build-up of knowledge and the optimization of such complex systems can benefit greatly from mathematical modelling [15], which is a powerful tool for studying complex systems. Here, the "virtual route" is followed, i.e. virtual experiments (or simulations) are used to study MBRs. The computational power available allows many virtual experiments to be performed in a short time frame. This is clearly advantageous relative to tedious laboratory experiments, especially for slow processes like bioprocesses [15]. Maere et al. [16] developed a simulator and compared control and operating strategies in terms of reactor volume, membrane filtration flux, aeration capacity and sludge flows. Suh et al. [17] used a similar simulator to investigate the coarse bubble aeration intensity during membrane filtration time and during idle-cleaning time. The main objective of the present work is to run experiments in silico to study a procedure for optimizing the operating parameters (aeration intensity, filtration flux, and filtration and coarse bubble aeration cycles) of a submerged membrane bioreactor (SMBR) using the energy consumption (EC) criterion as is done with real-world experiments. In silico optimization using the computer simulator not only consumes less time and resources but also allows us to study the behaviour of the intermediate parameters that cannot be regularly measured in real conditions, such as the resistances of the stable sludge cake layer and the dynamic sludge film, or the concentration of soluble microbial products (SMP), and thus contributes to a better understanding of the way the process operates (membrane fouling, COD, EC, etc.).
A statistical optimization method with an EC criterion is presented in the first part. The phenomena involved in MBR operation (biology coupled with complex fouling) are quite difficult to understand since there are several mechanisms that may have opposite influences depending on the range considered for the operating parameters [18]. So, in order to understand the results obtained, in a second part, the solutions found for the variation of EC and the transmembrane pressure (TMP) are refined by following the variations of certain operating parameters one by one. Ways to improve the operating conditions of MBRs have been studied several times, either experimentally [19] or through model-based approaches $[12,20,21]$. However, to the best of the authors' knowledge, this is the first time the use of a numerical (quadratic) optimization method employing in silico experiments for the EC of a SMBR for urban wastewater treatment has been accomplished.

\section{Materials and methods}

When designing, upgrading, retrofitting, operating and controlling wastewater treatment plants, consultant engineers are finding computer modelling and simulation of these plants and their specific technologies, such as MBRs, increasingly useful [22]. The work presented here used a simulator developed by González-Hernández et al. [23] by implementing the integrated model of an SMBR proposed by Zarragoitia et al. [24]. The simulator structure and utilities enabling the experiments to be run in silico are described in the following subsections.

\subsection{Description of the SMBR simulator}

The model of the SMBR computer simulator includes the biological degradation process employing activated sludge in combination with the physical separation process using membranes. This makes it possible to study the influence of the biological system on membrane fouling and vice versa. In this case, the two systems are linked by the production of SMP and total suspended solids (TSS) inside the bioreactor, these parameters being the main contributors to the membrane fouling process [24].

The SMBR computer simulator was initially intended to be used in teaching and research. The simulator graphical interface was built using the facilities provided by Delphi 2009 for object-oriented programming, in order to achieve a friendly graphical interface enabling the assignation and manipulation of different operating parameters, as well as observation of how 
the variables of interest behave over time [23]. A better description of the simulator can be found in González-Hernández et al. work [23].

\subsection{Operating conditions}

The experimental data of the pilot SMBR studied by Zarragoitia et al. [24] was used. The characteristics of the wastewater to be treated and the main parameters of this plant are shown in Table 1.

Many operating parameters (SRT, temperature, etc.) influence membrane fouling [6]. Since the objective of this work was energy optimization, the operating parameters studied were those concerning the filtration: average specific aeration intensity, average filtration flux, filtration and coarse bubble aeration cycles.

Suh et al. [17] concluded that the coarse bubble aeration and idle-cleaning times in MBRs must be optimized, so the present study evaluated two operating modes: sequential and non-sequential. The first occurs when the filtration time coincides with the time without coarse bubble aeration $\left(t_{\mathrm{f}}=t_{\mathrm{paBG}}\right)$ and the relaxation time coincides with the coarse bubble aeration time $\left(t_{\mathrm{pf}}=t_{\mathrm{aBG}}\right)$ (Fig. 1(a)), while the second occurs when the filtration and aeration cycles may or may not coincide during the SMBR operation (Fig. 1(b)).

\subsection{Optimization of the operating parameters}

To optimize the operating parameters of the SMBR pilot station, two experiment designs were used: a central composite rotatable design $2^{4}+2 \times 4+1$ for the sequential operating mode and a central composite rotatable design $2^{6-1}+2 \times 6+1$ for the non-sequential operating mode [25]. The independent variables and their ranges for each experimental design (Table 2) were selected in accordance with the ranges found in the literature $[18,26]$.

Currently, two of the most significant components of MBR running costs are membrane replacement and EC, and both relate to fouling [27]. Here, the EC criterion was used and fouling of the membrane system was only taken into account for a first step. The EC associated with membrane fouling was given by the filtration and aeration processes. The energy requirement for pumping permeate flow $\left(Q_{\text {eff }}\right)$ during the filtration period was evaluated using the modified expression suggested by Judd and Judd [28] considering a constant filtration flux:

$P_{\text {eff }, p}=\frac{1}{t_{1}-t_{0}} \int_{t_{0}}^{t_{1}} \frac{\operatorname{TMP}(t) Q_{\text {eff }}}{\eta} d t$

where $P_{\text {eff,p }}(\mathrm{kW})$ is the permeate pumping power requirement, TMP $(\mathrm{kPa})$ is the transmembrane pressure, $Q_{\text {eff }}\left(\mathrm{m}^{3} \mathrm{~s}^{-1}\right)$ is the effluent flow rate, $t_{0}$ and $t_{1}$ are the initial and the final times of pump operation, respectively, and $\eta$ is the permeate pump efficiency.

The computed aeration energy demand considered the power requirement in the case of adiabatic compression according to the following expression [29]:

$P_{\mathrm{w}, \mathrm{p}}=\frac{w R T}{0.283 e \mathrm{M}_{\mathrm{A}}}\left[\left(\frac{P_{2}}{P_{1}}\right)^{0.283}-1\right]$

where $P_{\mathrm{w}, \mathrm{p}}(\mathrm{kW})$ is the power requirement for each blower, $w$ is the mass flow of air $\left(\mathrm{kg} \mathrm{s}^{-1}\right), R$ is the gas constant for air $\left(8.314 \mathrm{~kJ} \mathrm{kmol}^{-1} \mathrm{~K}^{-1}\right), T$ is the absolute temperature $(\mathrm{K}), P_{1}$ and $P_{2}$ are the absolute inlet and outlet pressures (atm), respectively, $M_{\mathrm{A}}\left(\mathrm{kg} \mathrm{kmol}^{-1}\right)$ is the molar mass of air, 0.283 is a constant for air and $e$ is the blower efficiency (common range 0.7-0.9).

Table 1

Characteristics of wastewater treated and main parameters of the plant

Wastewater characteristics

\begin{tabular}{|c|c|c|c|c|c|c|}
\hline $\begin{array}{l}S_{\mathrm{B}} \\
(\mathrm{mgCOD} / \mathrm{L})\end{array}$ & $\begin{array}{l}S_{\mathrm{U}} \\
(\mathrm{mgCOD} / \mathrm{L})\end{array}$ & $\begin{array}{l}S_{\mathrm{SMP}} \\
(\mathrm{mgCOD} / \mathrm{L})\end{array}$ & $\begin{array}{l}\mathrm{XC}_{\mathrm{B}} \\
(\mathrm{mgCOD} / \mathrm{L})\end{array}$ & $\begin{array}{l}X_{\mathrm{OHO}} \\
(\mathrm{mgCOD} / \mathrm{L})\end{array}$ & $\begin{array}{l}X_{U} \\
(\mathrm{mgCOD} / \mathrm{L})\end{array}$ & $\begin{array}{l}X_{\mathrm{TSS}} \\
(\mathrm{mgTSS} / \mathrm{L})\end{array}$ \\
\hline 230 & 30 & 60 & 70 & 10 & 55 & 35 \\
\hline
\end{tabular}

Parameters of the bench-scale plant

Biological system

\begin{tabular}{llllllll}
\hline HRT (h) & SRT (d) & MLSS (mgTSS/L) & & $J\left(\mathrm{~m}^{3} \mathrm{~m}^{-2} \mathrm{~d}^{-1}\right)$ & $q_{\mathrm{a}}\left(\mathrm{L} \mathrm{m}^{-2} \mathrm{~s}^{-1}\right)$ & $A_{\mathrm{m}}\left(\mathrm{m}^{2}\right)$ & $d_{\mathrm{P}}(\mathrm{m})$ \\
\hline 3 & 30 & 7,500 & 0.3 & 6 & 0.3 & $1 \times 10^{-6}$ \\
\hline
\end{tabular}


(a)

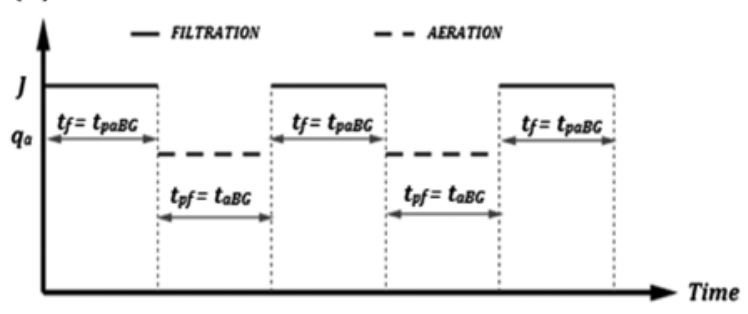

(b)

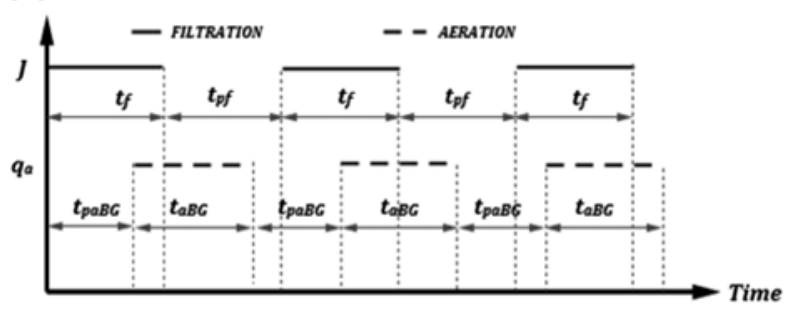

Fig. 1. Filtration and aeration cycles for the two operating modes: (a) sequential and (b) non-sequential.

Table 2

Ranges of the operating parameters used in the experimental design for the SMBR optimization $\left(\mathrm{SRT}=30 \mathrm{~d}, \mathrm{~T}=13^{\circ} \mathrm{C}\right.$ and $t_{\exp }=10 \mathrm{~d}$ )

\begin{tabular}{|c|c|c|c|}
\hline \multicolumn{2}{|c|}{ Sequential operating mode } & \multicolumn{2}{|c|}{ Non-sequential operating mode } \\
\hline Parameters & Ranges & Parameters & Ranges \\
\hline $\begin{array}{l}q_{\mathrm{am}} \\
t_{\mathrm{f}} \\
t_{\mathrm{f}} / t_{\mathrm{pf}} \\
J_{\mathrm{m}}\end{array}$ & $\begin{array}{l}0.041-0.277 \mathrm{~L} \mathrm{~m}^{-2} \mathrm{~s}^{-1} \\
60-1,080 \mathrm{~s} \\
0.33-8 \\
0.032-0.160 \mathrm{~m}^{3} \mathrm{~m}^{-2} \mathrm{~d}^{-1}\end{array}$ & $\begin{array}{l}q_{\mathrm{am}} \\
t_{\mathrm{f}} \\
t_{\mathrm{f}} / t_{\mathrm{pf}} \\
t_{\mathrm{aBG}} \\
t_{\mathrm{aBG}} / t_{\mathrm{paBG}} \\
J_{\mathrm{m}}\end{array}$ & $\begin{array}{l}0.041-0.277 \mathrm{~L} \mathrm{~m}^{-2} \mathrm{~s}^{-1} \\
60-1,080 \mathrm{~s} \\
0.33-8 \\
60-1,080 \mathrm{~s} \\
0.33-8 \\
0.032-0.160 \mathrm{~m}^{3} \mathrm{~m}^{-2} \mathrm{~d}^{-1}\end{array}$ \\
\hline
\end{tabular}

In this study, the total EC of the plant per $\mathrm{m}^{3}$ of permeate produced was used:

$\mathrm{EC}=\frac{P_{\mathrm{w}, \mathrm{p}} t_{\mathrm{ar}}+P_{\mathrm{eff}, \mathrm{p}} t_{\mathrm{fr}}}{\mathrm{FV}}$

where $\mathrm{EC}\left(\mathrm{kW} \mathrm{h} \mathrm{m}^{-3}\right)$ is the total energy consumption per $\mathrm{m}^{3}$ of produced permeate, $t_{\mathrm{ar}}(\mathrm{h})$ is the total time of compressor operation, $t_{\mathrm{fr}}(\mathrm{h})$ is the total time of pump operation and $\mathrm{FV}\left(\mathrm{m}^{3}\right)$ is the total volume of permeate produced.

\subsection{Statistical analysis of the results}

To optimize the EC function, the experimental data obtained in silico were adjusted to a polynomial of order 2. Determination of the model coefficients used the least squares method, minimizing the model adjustment Fisher value for a 95\% confidence level. The coefficient significance was evaluated using the Student distribution. The model adjustment was performed using a multiple regression analysis with backward stepwise variable selection [30]. In all cases, the correlation model coefficients, the standard estimation error and the mean absolute error were determined. Finally, the optimal values that minimized the EC were calculated using the statistical model obtained.

\section{Results and discussion}

\subsection{Preliminary results on the time of simulation}

The simulation time was fixed at $10 \mathrm{~d}$. As an example, Fig. 2 shows the TMP behaviour vs. time for two experiments. As can be seen, the behaviour was similar in both cases and the main difference was the time in which the critical TMP was reached. For the worst experiment, the TMP was $121.1 \mathrm{kPa}$ after $10 \mathrm{~d}$ of running. The critical TMP was fixed at $60 \mathrm{kPa}$ (represented by the dashed line) and, in this case, it was reached in $3 \mathrm{~d}$. This means that, in real conditions, the installation would have to be stopped to carry out chemical cleaning of the membrane.

\subsection{Optimization of the operating parameters of an $S M B R$}

\subsubsection{Optimization in sequential operating mode}

For the optimization study (Table 3), the operating parameters were mean aeration intensity, filtration time and the relation $t_{\mathrm{f}} / t_{\mathrm{pf}}$. The mean filtration flux was calculated and the TMP, filtrated volume and the EC were determined in silico.

The results obtained by means of a multiple regression analysis with backward stepwise variable selection gave a fitted model describing the relationship between EC and two independent variables 

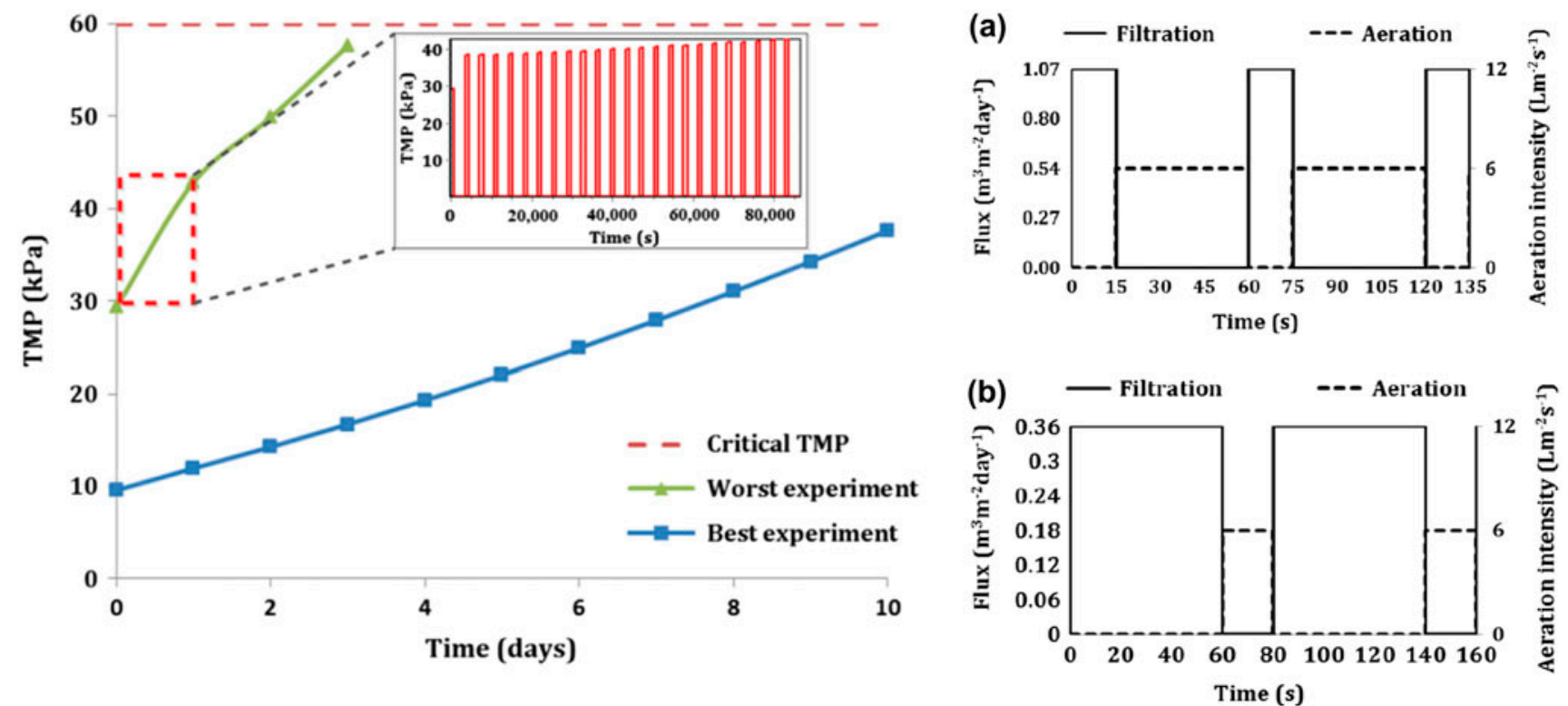

Fig. 2. Behaviour of TMP over time: (a) filtration/aeration sequence for an experiment in which the TMP passes the critical pressure (___- ) and (b) filtration/aeration sequence for an experiment in which the final TMP does not reach the critical pressure (_- - ).

Table 3

Central composite rotatable design $2^{4}+2 \times 4+1$ for the sequential operating mode (in italic, the best result for EC, exp. 17 and the worst, exp. 23)

\begin{tabular}{|c|c|c|c|c|c|c|c|}
\hline Exp. & $q_{\mathrm{am}}\left(\mathrm{L} \mathrm{m}^{-2} \mathrm{~s}^{-1}\right)$ & $t_{\mathrm{f}}(\mathrm{s})$ & $t_{\mathrm{f}} / t_{\mathrm{pf}}$ & $J_{\mathrm{m}}\left(\mathrm{m}^{3} \mathrm{~m}^{-2} \mathrm{~d}^{-1}\right)$ & $\mathrm{TMP}(\mathrm{kPa})$ & $\mathrm{FV}(\mathrm{L})$ & 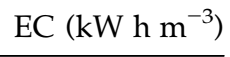 \\
\hline 1 & 0.089 & 267 & 1.88 & 0.060 & 6.47 & 176.28 & 1.1477 \\
\hline 2 & 0.229 & 267 & 1.88 & 0.060 & 5.92 & 176.28 & 2.9577 \\
\hline 3 & 0.089 & 873 & 1.88 & 0.060 & 6.51 & 176.51 & 1.1434 \\
\hline 4 & 0.229 & 873 & 1.88 & 0.060 & 5.95 & 176.51 & 2.9466 \\
\hline 5 & 0.089 & 267 & 6.45 & 0.060 & 5.35 & 182.05 & 1.0995 \\
\hline 6 & 0.229 & 267 & 6.45 & 0.060 & 4.85 & 182.05 & 2.8342 \\
\hline 7 & 0.089 & 873 & 6.45 & 0.060 & 5.36 & 181.88 & 1.1071 \\
\hline 8 & 0.229 & 873 & 6.45 & 0.060 & 4.86 & 181.88 & 2.8538 \\
\hline 9 & 0.089 & 267 & 1.88 & 0.130 & 24.20 & 411.32 & 0.4964 \\
\hline 10 & 0.229 & 267 & 1.88 & 0.130 & 21.05 & 411.32 & 1.2717 \\
\hline 11 & 0.089 & 873 & 1.88 & 0.130 & 24.39 & 411.85 & 0.4946 \\
\hline 12 & 0.229 & 873 & 1.88 & 0.130 & 21.24 & 411.86 & 1.2670 \\
\hline 13 & 0.089 & 267 & 6.45 & 0.130 & 17.82 & 390.10 & 0.5163 \\
\hline 14 & 0.229 & 267 & 6.45 & 0.130 & 15.44 & 390.10 & 1.3255 \\
\hline 15 & 0.089 & 873 & 6.45 & 0.130 & 17.87 & 389.74 & 0.5199 \\
\hline 16 & 0.229 & 873 & 6.45 & 0.130 & 15.50 & 389.74 & 1.3347 \\
\hline 17 & 0.041 & 570 & 4.17 & 0.100 & 12.72 & 290.24 & 0.3239 \\
\hline 18 & 0.277 & 570 & 4.17 & 0.100 & 9.88 & 290.24 & 2.1713 \\
\hline 19 & 0.159 & 60 & 4.17 & 0.100 & 10.61 & 291.90 & 1.2111 \\
\hline 20 & 0.159 & 1,080 & 4.17 & 0.100 & 10.63 & 290.39 & 1.2441 \\
\hline 21 & 0.159 & 570 & 0.33 & 0.100 & 39.21 & 290.67 & 1.2508 \\
\hline 22 & 0.159 & 570 & 8 & 0.100 & 10.23 & 293.47 & 1.2281 \\
\hline 23 & 0.159 & 570 & 4.17 & 0.030 & 2.25 & 96.75 & 3.7355 \\
\hline 24 & 0.159 & 570 & 4.17 & 0.160 & 24.32 & 483.74 & 0.7522 \\
\hline 25 & 0.159 & 570 & 4.17 & 0.100 & 10.57 & 290.24 & 1.2474 \\
\hline
\end{tabular}




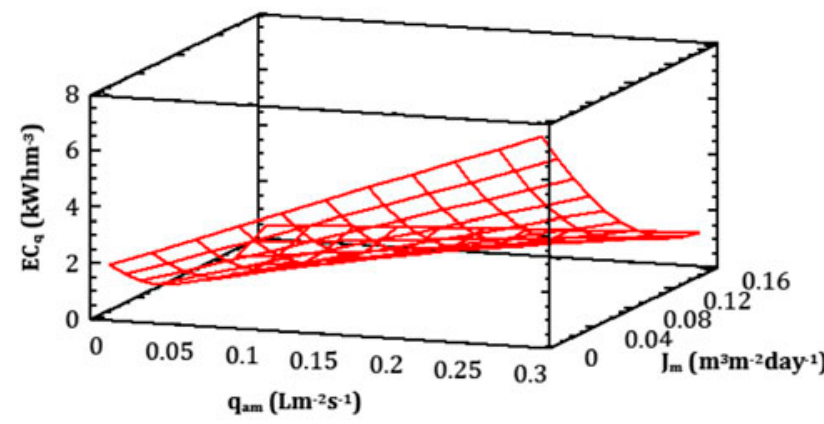

Fig. 3. Response surfaces of $\mathrm{EC}_{\mathrm{q}}$ for the sequential operating mode as a function of $q_{\mathrm{am}}$ and $J_{\mathrm{m}}\left(t_{\mathrm{f}}=60 \mathrm{~s}\right.$, $\left.t_{\mathrm{f}} / t_{\mathrm{pf}}=2.99\right)$.

( $q_{\mathrm{am}}$ and $J_{\mathrm{m}}$ ), with a statistically significant relationship between them at $99 \%$ confidence level and a correlation factor of $98 \%$. The equation of the fitted model was:

$$
\begin{aligned}
\mathrm{EC}_{\mathrm{q}}= & 1.8969+18.5396 q_{\mathrm{am}}-41.8191 J_{\mathrm{m}} \\
& -100.9660 q_{\mathrm{am}} \cdot J_{\mathrm{m}}+210.5030\left(J_{\mathrm{m}}\right)^{2}
\end{aligned}
$$

Fig. 3 shows the response surface of $\mathrm{EC}_{\mathrm{q}}$ as a function of $q_{\mathrm{am}}$ and $J_{\mathrm{m}}$.

Using this statistical model, the optimal operating conditions were found at $q_{\mathrm{am}}=0.042 \mathrm{~L} \mathrm{~m}^{-2} \mathrm{~s}^{-1}$, $t_{\mathrm{f}}=60 \mathrm{~s}, t_{\mathrm{f}} / t_{\mathrm{pf}}=2.99$ and $J_{\mathrm{m}}=0.117 \mathrm{~m}^{3} \mathrm{~m}^{-2} \mathrm{~d}^{-1}$. Using the simulator, this gave a minimum energy consumption of $\mathrm{EC}=0.2741 \mathrm{~kW} \mathrm{~h} \mathrm{~m}^{-3}$, a value $15.4 \%$ lower than the best value obtained from the design matrix (Table 2, line 17: $0.3239 \mathrm{~kW} \mathrm{~h} \mathrm{~m}^{-3}$ ).

The best $\mathrm{EC}_{\mathrm{q}}$ values were found for the lowest $q_{\mathrm{am}}$ value of the studied range (Fig. 3).

\subsubsection{Optimization in non-sequential operating mode}

For this optimization study, the operating parameters used in the previous study and two more parameters: $t_{\mathrm{aBG}}$ and the relation $t_{\mathrm{aBG}} / t_{\mathrm{paBG}}$, were employed. When the experimental design was analysed (Table 4), the EC varied from 0.327 to $3.728 \mathrm{~kW} \mathrm{~h} \mathrm{~m}^{-3}$.

Similarly to those for sequential operating mode, the results obtained by means of a multiple regression analysis with backward stepwise variable selection gave a fitted model that described the relationship between EC and two independent variables ( $q_{\mathrm{am}}$ and $J_{\mathrm{m}}$ ), with a statistically significant relationship between them at $99 \%$ confidence level and a correlation factor of $97 \%$. The equation of the fitted model was:

$$
\begin{aligned}
\mathrm{EC}_{\mathrm{q}}= & 2.3108+16.8481 q_{\mathrm{am}}-48.2315 J_{\mathrm{m}} \\
& -88.4491 q_{\mathrm{am}} \cdot J_{\mathrm{m}}+238.644\left(J_{\mathrm{m}}\right)^{2}
\end{aligned}
$$

The response surface of $\mathrm{EC}_{\mathrm{q}}$ is shown as a function of $q_{\mathrm{am}}$ and $J_{\mathrm{m}}$ in Fig. 4.

The optimal operating conditions were determined in the same way. The minimum EC was found at optimal values of $q_{\mathrm{am}}=0.041 \mathrm{~L} \mathrm{~m}^{-2} \mathrm{~s}^{-1}, t_{\mathrm{f}}=1,079 \mathrm{~s}$, $t_{\mathrm{f}} / t_{\mathrm{pf}}=1.46, t_{\mathrm{aBG}}=955 \mathrm{~s}, t_{\mathrm{aBG}} / t_{\mathrm{paBG}}=0.68$ and $J_{\mathrm{m}}=$ $0.098 \mathrm{~m}^{3} \mathrm{~m}^{-2} \mathrm{~d}^{-1}$. The value of $\mathrm{EC}=0.320 \mathrm{~kW} \mathrm{~h} \mathrm{~m}^{-3}$ is $2.3 \%$ lower than the minimum value of the experimental design matrix in non-sequential operating mode (Table 3, line 33: $0.327 \mathrm{~kW} \mathrm{~h} \mathrm{~m}^{-3}$ ).

As in the sequential operating mode, the values of aeration intensity and the mean filtration flux that gave a low $\mathrm{EC}$ were close to the low level of the range studied (Fig. 4).

\subsubsection{Comparison of the optimal operating conditions between the sequential and non-sequential operating modes}

Thanks to the simulator, almost 70 in silico experiments were performed in this study. Each lasted $15 \mathrm{~min}$ instead the $10 \mathrm{~d}$ to 1 month required for a real experiment. Such a comparison of durations points out the relevance of in silico experiments.

Table 4 sums up the results obtained. The optimal operating conditions of both operating modes were evaluated in the simulator at $10 \mathrm{~d}$ of operation and until the critical TMP (60 kPa) was reached. These results led to the conclusion that, according to the EC criterion employed, the sequential operating mode was more efficient, with an EC of $0.2741 \mathrm{~kW} \mathrm{~h} \mathrm{~m}^{-3}$, than the non-sequential mode, for which the EC was $0.3195 \mathrm{~kW} \mathrm{~h} \mathrm{~m}^{-3}$.

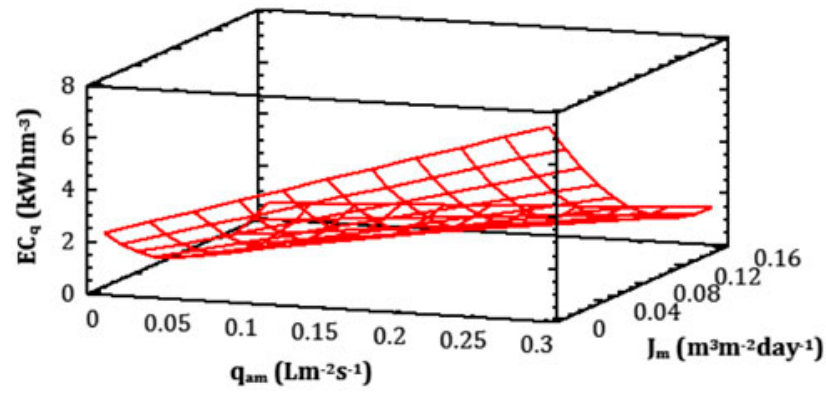

Fig. 4. Response surface of $\mathrm{EC}_{\mathrm{q}}$ for the non-sequential operating mode as a function of $q_{\mathrm{am}}$ and $J_{\mathrm{m}}\left(t_{\mathrm{f}}=1,079 \mathrm{~s}\right.$, $\left.t_{\mathrm{f}} / t_{\mathrm{pf}}=1.46, t_{\mathrm{aBG}}=955 \mathrm{~s}, t_{\mathrm{aBG}} / t_{\mathrm{paBG}}=0.68\right)$. 
Table 4

Central composite rotatable design $2^{6-1}+2 \times 6+1$ for the non-sequential operating mode (in italic the best result for EC (exp. 33), and the worst (exp. 43))

\begin{tabular}{|c|c|c|c|c|c|c|c|c|c|}
\hline Exp. & $q_{\mathrm{am}}\left(\mathrm{L} \mathrm{m}^{-2} \mathrm{~s}^{-1}\right)$ & $t_{\mathrm{f}}(\mathrm{s})$ & $t_{\mathrm{f}} / t_{\mathrm{pf}}$ & $t_{\mathrm{aBG}}(\mathrm{s})$ & $t_{\mathrm{aBG}} / t_{\mathrm{paBG}}$ & $J_{\mathrm{m}}\left(\mathrm{m}^{3} \mathrm{~m}^{-2} \mathrm{~d}^{-1}\right)$ & TMP (kPa) & FV (L) & $\mathrm{EC}\left(\mathrm{kW} \mathrm{h} \mathrm{\textrm {m } ^ { - 3 } )}\right.$ \\
\hline 1 & 0.109 & 356 & 2.55 & 356 & 2.55 & 0.069 & 6.00 & 207.15 & 1.200 \\
\hline 2 & 0.209 & 356 & 2.55 & 356 & 2.55 & 0.123 & 12.75 & 368.98 & 1.287 \\
\hline 3 & 0.109 & 784 & 2.55 & 356 & 2.55 & 0.123 & 12.95 & 368.68 & 0.676 \\
\hline 4 & 0.209 & 784 & 2.55 & 356 & 2.55 & 0.069 & 5.53 & 206.98 & 2.290 \\
\hline 5 & 0.109 & 356 & 5.78 & 356 & 2.55 & 0.123 & 10.83 & 367.93 & 0.677 \\
\hline 6 & 0.209 & 356 & 5.78 & 356 & 2.55 & 0.069 & 4.65 & 206.96 & 2.290 \\
\hline 7 & 0.109 & 784 & 5.78 & 356 & 2.55 & 0.069 & 4.86 & 207.08 & 1.200 \\
\hline 8 & 0.209 & 784 & 5.78 & 356 & 2.55 & 0.123 & 10.16 & 368.15 & 1.289 \\
\hline 9 & 0.109 & 356 & 2.55 & 784 & 2.55 & 0.123 & 12.97 & 368.98 & 0.675 \\
\hline 10 & 0.209 & 356 & 2.55 & 784 & 2.55 & 0.069 & 5.54 & 207.15 & 2.286 \\
\hline 11 & 0.109 & 784 & 2.55 & 784 & 2.55 & 0.069 & 6.01 & 206.98 & 1.200 \\
\hline 12 & 0.209 & 784 & 2.55 & 784 & 2.55 & 0.123 & 12.78 & 368.68 & 1.287 \\
\hline 13 & 0.109 & 356 & 5.78 & 784 & 2.55 & 0.069 & 4.86 & 206.96 & 1.200 \\
\hline 14 & 0.209 & 356 & 5.78 & 784 & 2.55 & 0.123 & 10.18 & 367.93 & 1.289 \\
\hline 15 & 0.109 & 784 & 5.78 & 784 & 2.55 & 0.123 & 10.86 & 368.15 & 0.676 \\
\hline 16 & 0.209 & 784 & 5.78 & 784 & 2.55 & 0.069 & 4.66 & 207.08 & 2.286 \\
\hline 17 & 0.109 & 356 & 2.55 & 356 & 5.78 & 0.123 & 11.13 & 368.98 & 0.674 \\
\hline 18 & 0.209 & 356 & 2.55 & 356 & 5.78 & 0.069 & 5.04 & 207.15 & 2.289 \\
\hline 19 & 0.109 & 784 & 2.55 & 356 & 5.78 & 0.069 & 5.21 & 206.98 & 1.198 \\
\hline 20 & 0.209 & 784 & 2.55 & 356 & 5.78 & 0.123 & 10.57 & 368.68 & 1.288 \\
\hline 21 & 0.109 & 356 & 5.78 & 356 & 5.78 & 0.069 & 4.46 & 206.96 & 1.197 \\
\hline 22 & 0.209 & 356 & 5.78 & 356 & 5.78 & 0.123 & 9.07 & 367.93 & 1.290 \\
\hline 23 & 0.109 & 784 & 5.78 & 356 & 5.78 & 0.123 & 9.34 & 368.15 & 0.675 \\
\hline 24 & 0.209 & 784 & 5.78 & 356 & 5.78 & 0.069 & 4.25 & 207.08 & 2.289 \\
\hline 25 & 0.109 & 356 & 2.55 & 784 & 5.78 & 0.069 & 5.21 & 207.15 & 1.197 \\
\hline 26 & 0.209 & 356 & 2.55 & 784 & 5.78 & 0.123 & 10.57 & 368.98 & 1.288 \\
\hline 27 & 0.109 & 784 & 2.55 & 784 & 5.78 & 0.123 & 11.14 & 368.68 & 0.675 \\
\hline 28 & 0.209 & 784 & 2.55 & 784 & 5.78 & 0.069 & 5.05 & 206.98 & 2.292 \\
\hline 29 & 0.109 & 356 & 5.78 & 784 & 5.78 & 0.123 & 9.32 & 367.93 & 0.676 \\
\hline 30 & 0.209 & 356 & 5.78 & 784 & 5.78 & 0.069 & 4.24 & 206.96 & 2.292 \\
\hline 31 & 0.109 & 784 & 5.78 & 784 & 5.78 & 0.069 & 4.47 & 207.08 & 1.197 \\
\hline 32 & 0.209 & 784 & 5.78 & 784 & 5.78 & 0.123 & 9.07 & 368.15 & 1.290 \\
\hline 33 & 0.041 & 570 & 4.17 & 570 & 4.17 & 0.096 & 8.35 & 287.83 & 0.327 \\
\hline 34 & 0.277 & 570 & 4.17 & 570 & 4.17 & 0.096 & 7.13 & 287.83 & 2.190 \\
\hline 35 & 0.159 & 60 & 4.17 & 570 & 4.17 & 0.096 & 7.24 & 289.46 & 1.248 \\
\hline 36 & 0.159 & 1,080 & 4.17 & 570 & 4.17 & 0.096 & 7.25 & 287.97 & 1.254 \\
\hline 37 & 0.159 & 570 & 0.33 & 570 & 4.17 & 0.096 & 26.29 & 288.43 & 1.257 \\
\hline 38 & 0.159 & 570 & 8.00 & 570 & 4.17 & 0.096 & 6.57 & 288.14 & 1.253 \\
\hline 39 & 0.159 & 570 & 4.17 & 60 & 4.17 & 0.096 & 7.19 & 287.83 & 1.262 \\
\hline 40 & 0.159 & 570 & 4.17 & 1,080 & 4.17 & 0.096 & 7.24 & 287.83 & 1.255 \\
\hline 41 & 0.159 & 570 & 4.17 & 570 & 0.33 & 0.096 & 11.10 & 287.83 & 1.257 \\
\hline 42 & 0.159 & 570 & 4.17 & 570 & 8.00 & 0.096 & 6.60 & 287.83 & 1.258 \\
\hline 43 & 0.159 & 570 & 4.17 & 570 & 4.17 & 0.032 & 1.92 & 96.75 & 3.728 \\
\hline 44 & 0.159 & 570 & 4.17 & 570 & 4.17 & 0.160 & 15.35 & 478.90 & 0.757 \\
\hline 45 & 0.159 & 570 & 4.17 & 570 & 4.17 & 0.096 & 7.44 & 287.83 & 1.255 \\
\hline
\end{tabular}

However, some remarks may be necessary:

(1) First, the results presented in Table 5 show that this EC criterion is not the only parameter that should be considered; the volume filtered and the time to reach the critical TMP also have their importance.

(2) At $10 \mathrm{~d}$ of operation in the sequential operating mode, the system filtered $16 \%$ more water than in a non-sequential operating mode. This 
Table 5

Comparison of optimal operating conditions between sequential and non-sequential operating modes

\begin{tabular}{|c|c|c|c|c|c|c|}
\hline \multirow[b]{2}{*}{ Operating mode } & \multicolumn{3}{|c|}{ MBR operation at $10 \mathrm{~d}$} & \multicolumn{3}{|c|}{$\begin{array}{l}\text { MBR operation until the critical TMP } \\
(60 \mathrm{kPa}) \text { is reached }\end{array}$} \\
\hline & $\mathrm{TMP}(\mathrm{kPa})$ & $\mathrm{FV}(\mathrm{L})$ & $\mathrm{EC}\left(\mathrm{kW} \mathrm{h} \mathrm{m} \mathrm{h}^{-3}\right)$ & Time $(\mathrm{d})$ & $\mathrm{FV}(\mathrm{L})$ & $\mathrm{EC}\left(\mathrm{kW} \mathrm{h} \mathrm{\textrm {m } ^ { - 3 } )}\right.$ \\
\hline Sequential & 18.29 & 351 & 0.2741 & 36 & 1,263 & 0.2802 \\
\hline Non-sequential & 16.66 & 294 & 0.3195 & 42 & 1,234 & 0.3261 \\
\hline
\end{tabular}

would have an impact on the bioreactor investment. In the same period of time, a $9 \%$ lower TMP was obtained for the non-sequential operating mode.

(3) When the MBR operation was evaluated until the critical TMP was reached, in non-sequential mode, the system worked for six more days (plus 17\%) than in sequential operating mode, and thus filtered almost the same volume of water as that produced in the sequential operating mode.

(4) This first quadratic optimization part screened the main requirements for good running of an SMBR and discriminated among the influential operating parameters. However, the optimization criterion would be improved by including elements related to the bioreactor investment costs, and the cost of chemical cleaning of the membrane and its replacement at the end of its lifetime.

(5) Moreover, since the non-sequential domain of parameter variation includes the sequential one, it may appear surprising that the results minimizing the EC are not smaller than or equal to those found in the non-sequential case. This can be explained from a mathematical point of view, since the approximation made by the quadratic function is not the same in both cases.

For all these reasons, after this whole range screening, it would be worthwhile to study the exact solutions from the results obtained.

\subsection{Refining solutions}

Using the optimal running conditions obtained in the optimization study above, the influence of the operating parameters on the TMP and EC obtained for a running time of $10 \mathrm{~d}$ were studied. To do this, each operating parameter was varied in the studied range, while keeping the other variables constant. Two values of $t_{\mathrm{f}}$ were evaluated, 60 and 1,079 s, which correspond to the values of this parameter for the optima in sequential and non-sequential modes, respectively. For non-sequential in silico experiments, two values of the $\left(t_{\mathrm{f}}, t_{\mathrm{aBG}}\right)$ pair were used $(60,20 \mathrm{~s})$ and $(1,079,955 \mathrm{~s})$, which correspond to the values of these parameters for optimal running in sequential and non-sequential modes, respectively.

\subsubsection{Influence of the mean filtration flux and the mean aeration intensity on membrane fouling and EC}

In the previous part, two operating parameters were found to have a great influence on EC: the mean filtration flux and the mean aeration intensity. The influence of their variation on the TMP and EC were studied and the results are presented in Fig. 5.

It can be observed that:

(1) $t_{\mathrm{f}}$ has no impact on the results,

(2) as could be expected, the mean flux has a huge impact on TMP: the higher $J_{\mathrm{m}}$, the higher the TMP,

(3) as could also be expected, the mean aeration intensity has a huge impact on EC: the higher $q_{\mathrm{am}}$, the higher EC,

(4) at $J_{\mathrm{m}}=0.117$ and $0.1 \mathrm{~m}^{3} \mathrm{~m}^{-2} \mathrm{~d}^{-1}$ for sequential and non-sequential modes, respectively, the local EC minimum value obtained in the optimization part is not observed; the higher the flux, the lower EC. EC does not seem to be influenced by these changes of operating conditions,

(5) there is a small decrease in the TMP with mean aeration intensity,

(6) $J_{m}$ has a more pronounced influence on TMP, while $q_{\text {am }}$ has more influence on EC,

(7) the minimum values of EC are close to the value obtained in the optimization part in sequential mode, for both sequential and non-sequential modes.

For both parameters, a balance should be found between a lower TMP and a lower EC. From Fig. 5(a), 

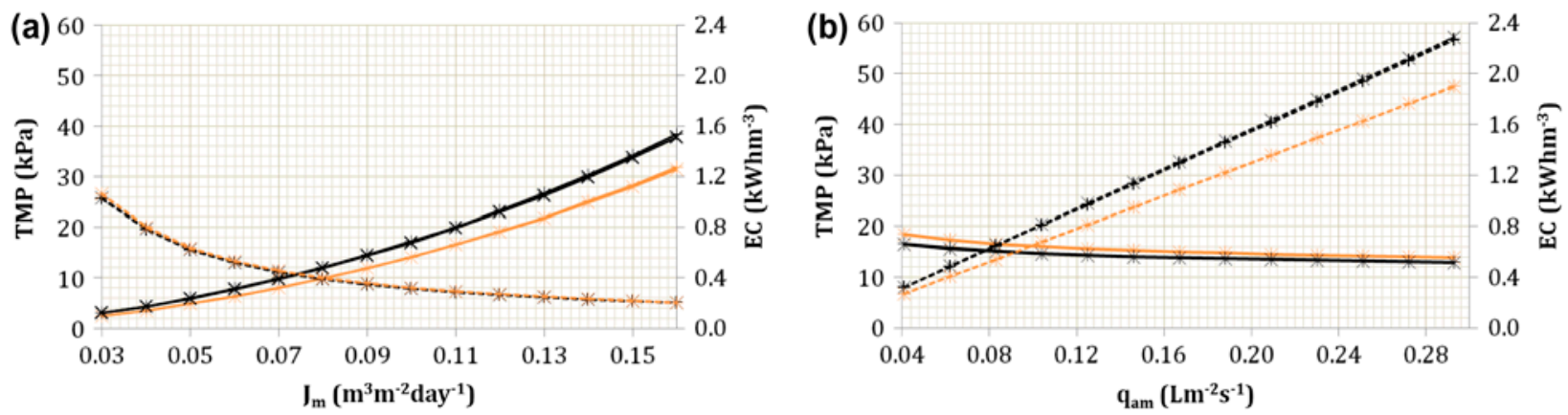

Fig. 5. Influence of (a) the mean filtration flux and (b) the mean aeration intensity on TMP and EC working in sequential $\left(t_{\mathrm{f}}=60 \mathrm{~s}:-x-\mathrm{TMP}\right.$ and $-x_{-}-\mathrm{EC}, t_{\mathrm{f}}=1,079 \mathrm{~s}:-\mathrm{TMP}_{-}$and $-+-\mathrm{EC}, t_{\mathrm{f}} / t_{\mathrm{pf}}=2.99, q_{\mathrm{am}}=0.042 \mathrm{~L} \mathrm{~m} \mathrm{~m}^{-2} \mathrm{~s}^{-1}$, $\left.J_{\mathrm{m}}=0.117 \mathrm{~m}^{3} \mathrm{~m}^{-2} \mathrm{~d}^{-1}\right)$ and non-sequential operating modes $\left(t_{\mathrm{f}}=60 \mathrm{~s}\right.$ and $t_{\mathrm{aBG}}=20 \mathrm{~s}:-\mathrm{x}-\mathrm{TMP}$ and $--\mathrm{x}--\mathrm{EC}, t_{\mathrm{f}}$ $=1,079 \mathrm{~s}$ and $t_{\mathrm{aBG}}=955 \mathrm{~s}:-+-\mathrm{TMP}$ and $-+--\quad \mathrm{EC}, t_{\mathrm{f}} / t_{\mathrm{pf}}=1.46, t_{\mathrm{aBG}} / t_{\mathrm{paBG}}=0.68, \quad q_{\mathrm{am}}=0.041 \mathrm{~L} \mathrm{~m}^{-2} \mathrm{~s}^{-1}$, $\left.J_{\mathrm{m}}=0.098 \mathrm{~m}^{3} \mathrm{~m}^{-2} \mathrm{~d}^{-1}\right)$.

it seems advisable for designers to plan a function at the beginning of the linear part of TMP, which is around $J_{\mathrm{m}}=0.09 \mathrm{~m}^{3} \mathrm{~m}^{-2} \mathrm{~d}^{-1}$.

This result confirms that, to improve this work, a new optimization criterion including chemical cleaning and investment should allow a better considered choice to be made.

However, these two parameters do not have the same function since $J_{\mathrm{m}}$ is usually fixed by the design of the bioreactor and wastewater treatment needs, whereas $q_{\mathrm{am}}$ may be adjusted. So, even if $q_{\mathrm{am}}$ has little influence on TMP, and its variations are costly, it is worth studying, especially as its influence is greater when $J_{\mathrm{m}}$ is not optimized (Figs. 3 and 4).

An analysis of the filtration resistances (Fig. 6) shows that the main influence comes from the static cake resistance which:

(1) is almost proportional to the mean filtration flux,

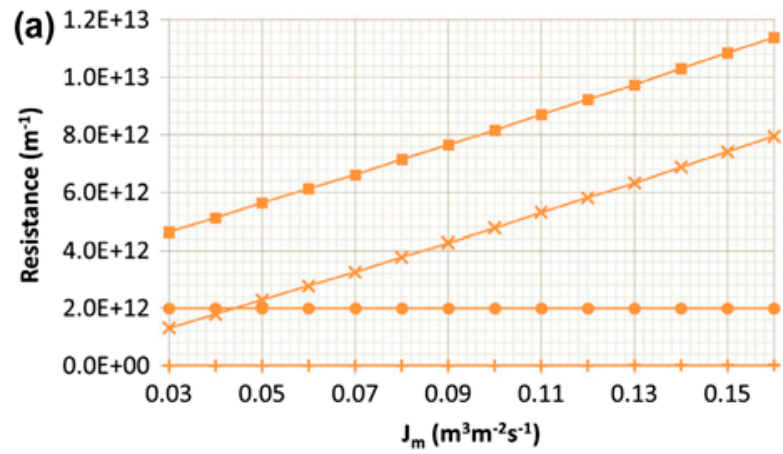

(2) has a first part that decreases strongly with the mean aeration and a second part that is quasi linear.

These behaviours are consistent with the TMP evolution.

The slight influence of $q_{\mathrm{am}}$ on TMP suggests that the study should be steered towards the influence of filtration and coarse bubble aeration cycles on membrane fouling.

\subsubsection{Influence of filtration and coarse bubble aeration cycles on membrane fouling and EC}

In this study, all the operating parameters were maintained constant except for the instantaneous filtration flux and the instantaneous aeration intensity, which were varied in order to filter the same volume of water and to use the same quantity of air in all the

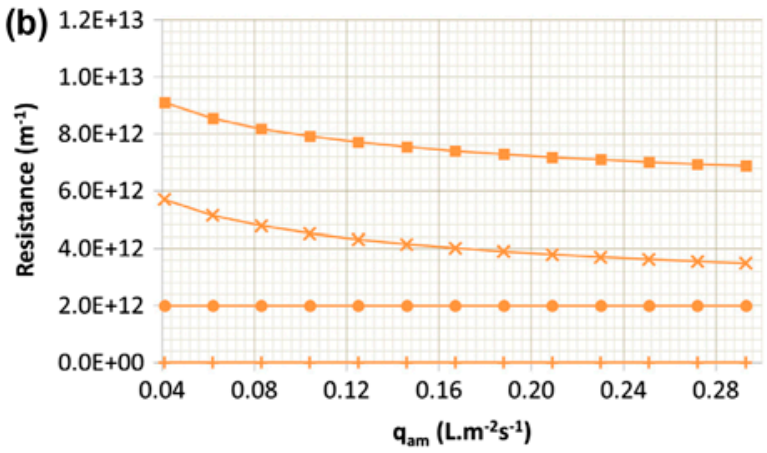

Fig. 6. Influence of (a) the mean filtration flux $\left(q_{\mathrm{am}}=0.042 \mathrm{~L} \mathrm{~m}^{-2} \mathrm{~s}^{-1}\right)$ and (b) the mean aeration intensity $\left(J_{\mathrm{m}}=0.117 \mathrm{~m}^{3} \mathrm{~m}^{-2} \mathrm{~d}^{-1}\right)$ on filtration resistances working in sequential mode (_- _ total resistance, - - $x_{-}-$static cake resistance, - - - dynamic cake resistance and - - pore resistance), $t_{\mathrm{f}} / t_{\mathrm{pf}}=2.99$. 
simulations. For this reason, in all the simulations, the EC associated with the aeration was the same, whereas the EC of the filtration pump changed because of TMP variations. To increase the ratio $t_{\mathrm{f}} / t_{\mathrm{pf}}$, $t_{\mathrm{f}}$ was fixed while $t_{\mathrm{pf}}$ was reduced.

3.3.2.1. In sequential operating mode. Fig. 7 presents the variations of TMP, EC, $J$ and $q_{\mathrm{a}}$ vs. the ratio $t_{\mathrm{f}} / t_{\mathrm{pf}}$

It can be observed that:

(1) TMP and EC do not depend on $t_{\mathrm{f}}$ (Fig. 7(a)),

(2) TMP and EC decrease with increasing $t_{\mathrm{f}} / t_{\mathrm{pf}}$. The global decrease in TMP can be explained by the decrease in $J$ and/or by the increase in $q_{\mathrm{a}}$ (Fig. 7(b)) and their influence on TMP. The global decrease in EC can be explained by the influence of TMP.

(3) In the first range, when $t_{\mathrm{f}} / t_{\mathrm{pf}}$ is below 0.5 :

(a) TMP decreases sharply (Fig. 7(a)), which may be a result of large variations in the instantaneous filtration flux (Fig. 7(b)) since the variation of the cake mass is a non-linear function of the instantaneous filtration flux.

(b) EC decreases slowly, which may be due to (i) the fact that the suction pump EC is small compared to the aeration EC, (ii) the influence of TMP on EC depends on an integration over time and the TMP decrease is exponential.

(4) For $t_{\mathrm{f}} / t_{\mathrm{pf}}$ greater than 1, TMP and EC hardly change with increments of $t_{\mathrm{f}} / t_{\mathrm{pf}}$.

(5) The minimum values of EC confirm the values obtained in the optimization part.

Therefore, as $t_{\mathrm{f}}$ does not significantly influence TMP and EC, this parameter can be fixed at the value most appropriate for the performance of the equipment used for the filtration and aeration cycles at values of $t_{\mathrm{f}} / t_{\mathrm{pf}} \geq 0.5$. A balance should be found between the capacity of the pump, giving $J$, and the capacity of the compressor, giving $q_{\mathrm{a}}$ (Fig. 7(b)). The inclusion of the capacities of this equipment in the investment part of the optimization criterion should allow a more considered choice to be made.

3.3.2.2. In non-sequential operating mode. For a nonsequential operating mode, the results are presented in Fig. 8.

It can be noted that:

(1) TMP and EC do not depend on $t_{\mathrm{f}}$ and $t_{\mathrm{aBG}}$ (Fig. 8(a) and (c)).

(2) The behaviour of TMP and EC is similar for the influence of $t_{\mathrm{f}} / t_{\mathrm{pf}}$ (and $J$ ) in the non-sequential mode (Fig. 8(c) and (d)) and in the sequential mode (Fig. 7(a) and (b)) and the same remarks can be made, whereas the behaviour of TMP and EC shows differences for the influence of $t_{\mathrm{aGB}} / t_{\mathrm{paGB}}\left(\right.$ and $q_{\mathrm{a}}$ ) (Fig. 8(a) and (b)):

(a) TMP decreases with increasing $t_{\mathrm{aBG}} /$ $t_{\mathrm{paBG}}$ and with decreasing $q_{\mathrm{a}}$, which shows that the time of aeration has more influence on TMP limitation than its instantaneous intensity.

(b) The influence of $t_{\mathrm{aBG}} / t_{\mathrm{paBG}}$ on $\mathrm{EC}$ is insignificant.

(c) The influence of $t_{\mathrm{f}} / t_{\mathrm{pf}}$ (and $J$ ) on TMP is more significant than the influence of $t_{\mathrm{aBG}} / t_{\mathrm{paBG}}$. It can be concluded that, when they are used together, the influence of $t_{\mathrm{f}} / t_{\mathrm{pf}}$ (and $J$ ) annihilates the effect of $t_{\mathrm{aGB}} / t_{\mathrm{paGB}}$ (and $q_{\mathrm{a}}$ )

(3) The minimum values of EC confirm the value obtained in the optimization part for the non-sequential mode.
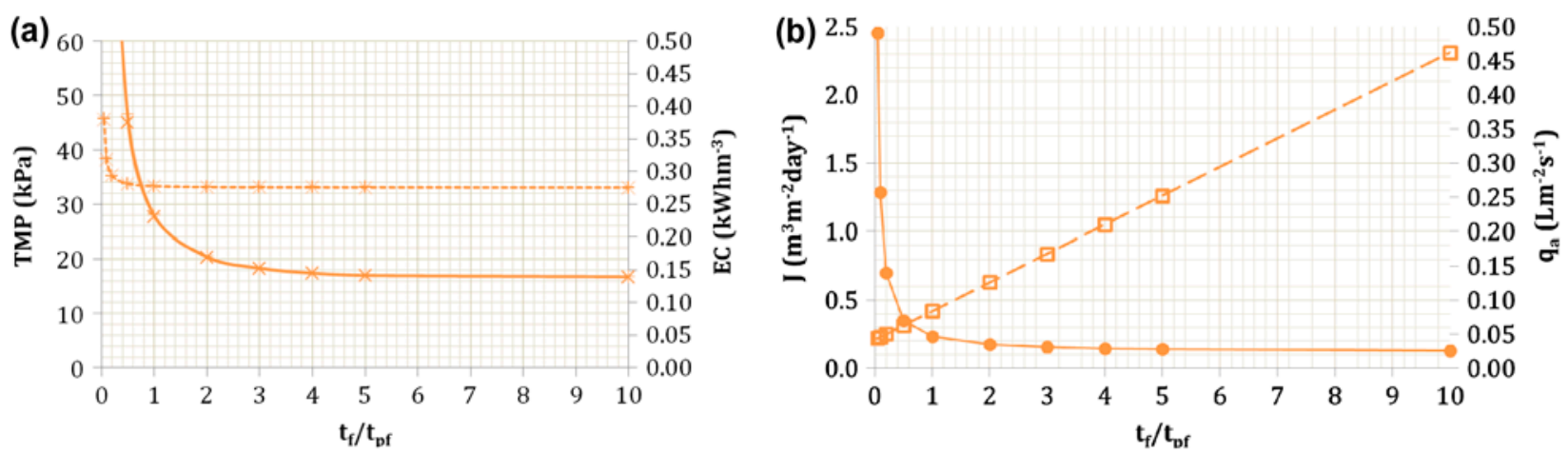

Fig. 7. Influence of the ratio $t_{\mathrm{f}} / t_{\mathrm{pf}}$ on (a) TMP $\left(--x_{-}-t_{\mathrm{f}}=60 \mathrm{~s},-+-t_{\mathrm{f}}=1,079 \mathrm{~s}\right)$ and $\mathrm{EC}\left(--x_{--} t_{\mathrm{f}}=60 \mathrm{~s},--+--\right.$ $\left.t_{\mathrm{f}}=1,079 \mathrm{~s}\right),(\mathrm{b}) J_{(-\infty)}$ and $q_{\mathrm{a}}(---)$ for the sequential operating mode $-q_{\mathrm{am}}=0.042 \mathrm{~L} \mathrm{~m}^{-2} \mathrm{~s}^{-1}$ and $\mathrm{J}_{\mathrm{m}}=0.117 \mathrm{~m}^{3} \mathrm{~m}^{-2} \mathrm{~d}^{-1}$. 

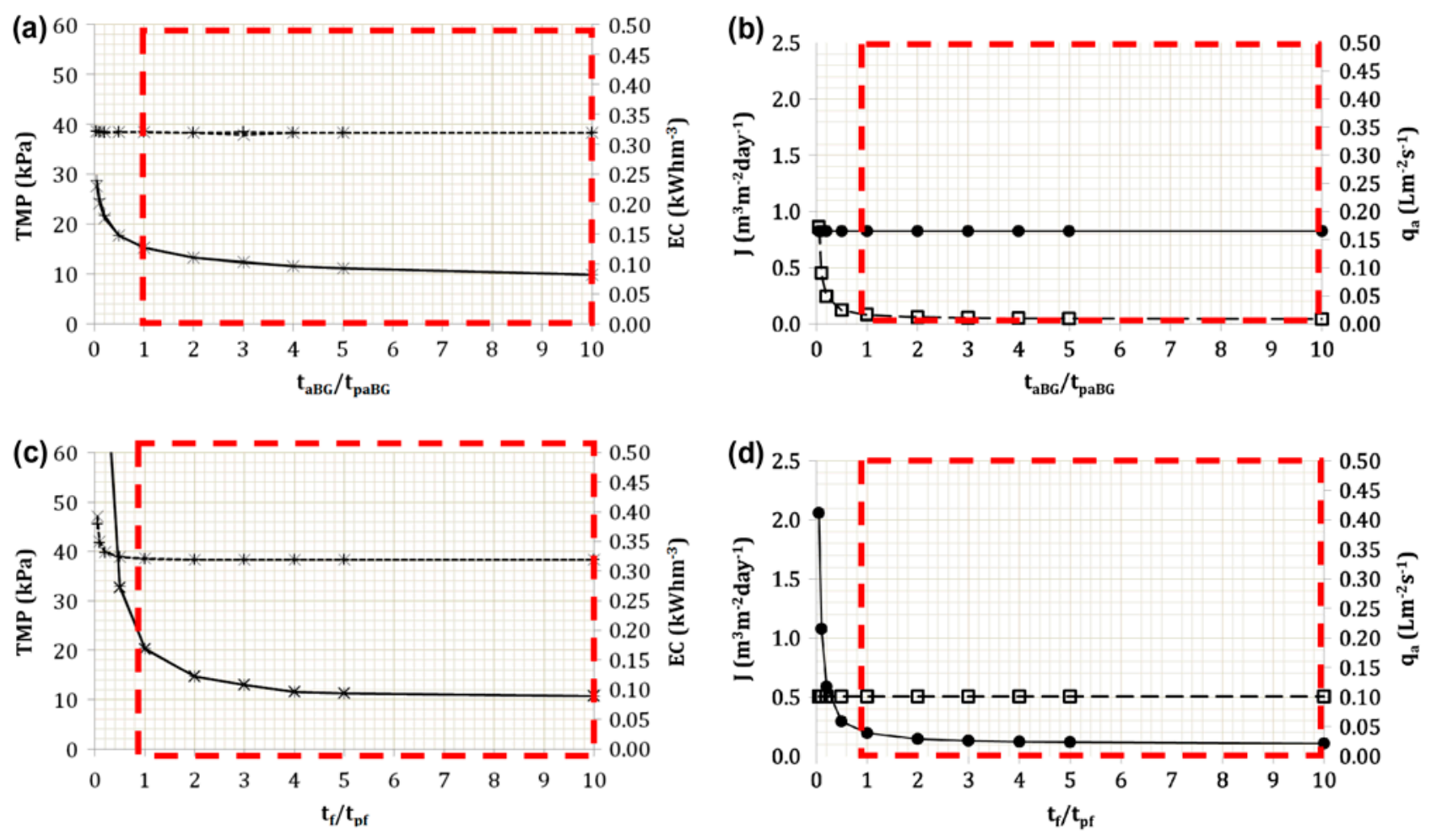

Fig. 8. In non-sequential operation, (a) TMP and EC and (b) J and $q_{\mathrm{a}}$ vs. the ratio $t_{\mathrm{aBG}} / t_{\mathrm{paBG}}$ (c) TMP and EC and (d) $J$ and $q_{\mathrm{a}}$ vs. the ratio $t_{\mathrm{f}} / t_{\mathrm{pf}}-\mathrm{TMP}\left(-\mathrm{x}-t_{\mathrm{aBG}}=20 \mathrm{~s}\right.$ and $t_{\mathrm{f}}=60 \mathrm{~s},-+-t_{\mathrm{f}}=1,079 \mathrm{~s}$ and $\left.t_{\mathrm{aBG}}=955 \mathrm{~s}\right), \mathrm{EC}\left(--\mathrm{x}--t_{\mathrm{f}}=60 \mathrm{~s}\right.$ and $t_{\mathrm{aBG}}=20 \mathrm{~s},--+-t_{\mathrm{f}}=1,079 \mathrm{~s}$ and $\left.t_{\mathrm{aBG}}=955 \mathrm{~s}\right), \mathrm{J}(-\bullet-), q_{\mathrm{a}}(--\square-), q_{\mathrm{am}}=0.041 \mathrm{~L} \mathrm{~m}^{-2} \mathrm{~s}^{-1}$ and $J_{\mathrm{m}}=0.098 \mathrm{~m}^{3} \mathrm{~m}^{-2} \mathrm{~d}^{-1}$.

Table 6

Synthesis of the influence of operating parameters on TMP and EC.

\begin{tabular}{|c|c|c|c|c|c|}
\hline & \multirow{2}{*}{$\begin{array}{l}\text { Operating mode } \\
\text { Response variable }\end{array}$} & \multicolumn{2}{|c|}{ Sequential } & \multicolumn{2}{|c|}{ Non-sequential } \\
\hline & & TMP & $\mathrm{EC}$ & TMP & $\mathrm{EC}$ \\
\hline \multirow[t]{6}{*}{ With rising values of the operating variables } & $J_{\mathrm{am}}$ & $\uparrow$ & $\downarrow$ & $\uparrow$ & $\downarrow$ \\
\hline & $q_{\mathrm{am}}$ & $\downarrow$ & $\uparrow$ & $\downarrow$ & $\uparrow$ \\
\hline & $t_{\mathrm{f}}$ & $\mathrm{x}$ & $\mathrm{x}$ & $\mathrm{x}$ & $\mathrm{x}$ \\
\hline & $t_{\mathrm{f}} / t_{\mathrm{pf}}$ & $\downarrow$ & $\downarrow$ & $\downarrow$ & $\downarrow$ \\
\hline & $t_{\mathrm{aBG}}$ & & & $x$ & $x$ \\
\hline & $t_{\mathrm{aBG}} / t_{\mathrm{paBG}}$ & & & $\downarrow$ & $X$ \\
\hline
\end{tabular}

Note: X: No influence.

In this non-sequential operating mode, for the optimal operating conditions found in this study, the most suitable option to obtain the lowest values of EC and TMP is to work:

(1) at high values of $t_{\mathrm{f}} / t_{\mathrm{pf}}$, at least above 1 , with low values of instantaneous filtration flux (Fig. 8(c) and (d)) as in sequential operating mode,
(2) but with high values of $t_{\mathrm{aBG}} / t_{\mathrm{paBG}}$, at least above 1 , and low values of $q_{\mathrm{a}}$ (Fig. 8(a) and (b)).

\subsubsection{Synthesis}

The use of in silico experiments allowed the operating parameters of an SMBR to be screened. From the energy point of view, the most influential parameters were $J_{\mathrm{m}}>q_{\mathrm{am}}>J>q_{\mathrm{a}}$, whereas $t_{\mathrm{f}} / t_{\mathrm{pf}}, t_{\mathrm{aBG}} / t_{\mathrm{paBG}}, t_{\mathrm{f}}$ and 
$t_{\mathrm{aBG}}$ had negligible influence. This showed that, even if the solutions obtained by a quadratic optimization method were not the real minima, the method gave a good range of operating parameters for low energy expenditure. Moreover, this study provided a good appreciation of the influential parameters, and the zones in which operating parameters influenced the EC criterion and the TMP. Table 6 summarizes the influence of operating parameters on TMP and EC for both operating modes studied.

\section{Conclusions}

Using in silico experiments, a numerical optimization study of the EC of a MBR for wastewater treatment was carried out.

With the quadratic approach, minimum values of EC of $0.27 \mathrm{~kW} \mathrm{~h} \mathrm{~m}^{-3}$ and $0.32 \mathrm{~kW} \mathrm{~h} \mathrm{~m}^{-3}$ were obtained for the sequential $\left(q_{\mathrm{am}}=0.042 \mathrm{~L} \mathrm{~m}^{-2} \mathrm{~s}^{-1}, t_{\mathrm{f}}=60 \mathrm{~s}, t_{\mathrm{f}} / t_{\mathrm{pf}}=\right.$ 2.99 and $J_{\mathrm{m}}=0.117 \mathrm{~m}^{3} \mathrm{~m}^{-2} \mathrm{~d}^{-1}$ ) and non-sequential $\left(q_{\mathrm{am}}=0.041 \mathrm{~L} \mathrm{~m}^{-2} \mathrm{~s}^{-1}, t_{\mathrm{f}}=1,079 \mathrm{~s}, t_{\mathrm{f}} / t_{\mathrm{pf}}=1.46, t_{\mathrm{aBG}}=\right.$ $955 \mathrm{~s}, t_{\mathrm{aBG}} / t_{\mathrm{paBG}}=0.68$ and $J_{\mathrm{m}}=0.098 \mathrm{~m}^{3} \mathrm{~m}^{-2} \mathrm{~d}^{-1}$ ) operating modes, respectively. The most significant parameters were the mean filtration flux, $J_{\mathrm{m}}$, and the mean aeration intensity, $q_{\mathrm{am}}$.

Using the optimal operating conditions found here, a study of the influence of mean filtration flux, mean aeration flow rate, and filtration and aeration cycles on the membrane fouling and the EC in an SMBR showed that:

(1) for both operating modes, filtration time and coarse bubble aeration time had no significant influence on the TMP and EC,

(2) the minimum EC values were obtained by working with the maximum value of the mean filtration flux and the minimum value of the mean aeration intensity in the ranges studied. However, these operating conditions led to rapid membrane fouling,

(3) although the optimization showed that the sequential mode would consume less energy, a study of refined solutions showed that operating modes seemed to have little influence,

(4) no significant variations of EC were obtained for values of $t_{\mathrm{f}} / t_{\mathrm{pf}}>1$ and $t_{\mathrm{aBG}} / t_{\mathrm{paBG}}>0.33$,

(5) at low values, $t_{\mathrm{f}} / t_{\mathrm{pf}}$ had considerable influence on TMP, which argues in favour of working with $t_{\mathrm{f}} / t_{\mathrm{pf}}>1$.

In future work, all improvements in the simulator would make the results more precise. Use of an economic criterion including: chemical cleaning, the investments depending on the volume of the bioreactor, and the capacities of the permeate pump and of the coarse bubble aeration compressor, would allow broader optimization.

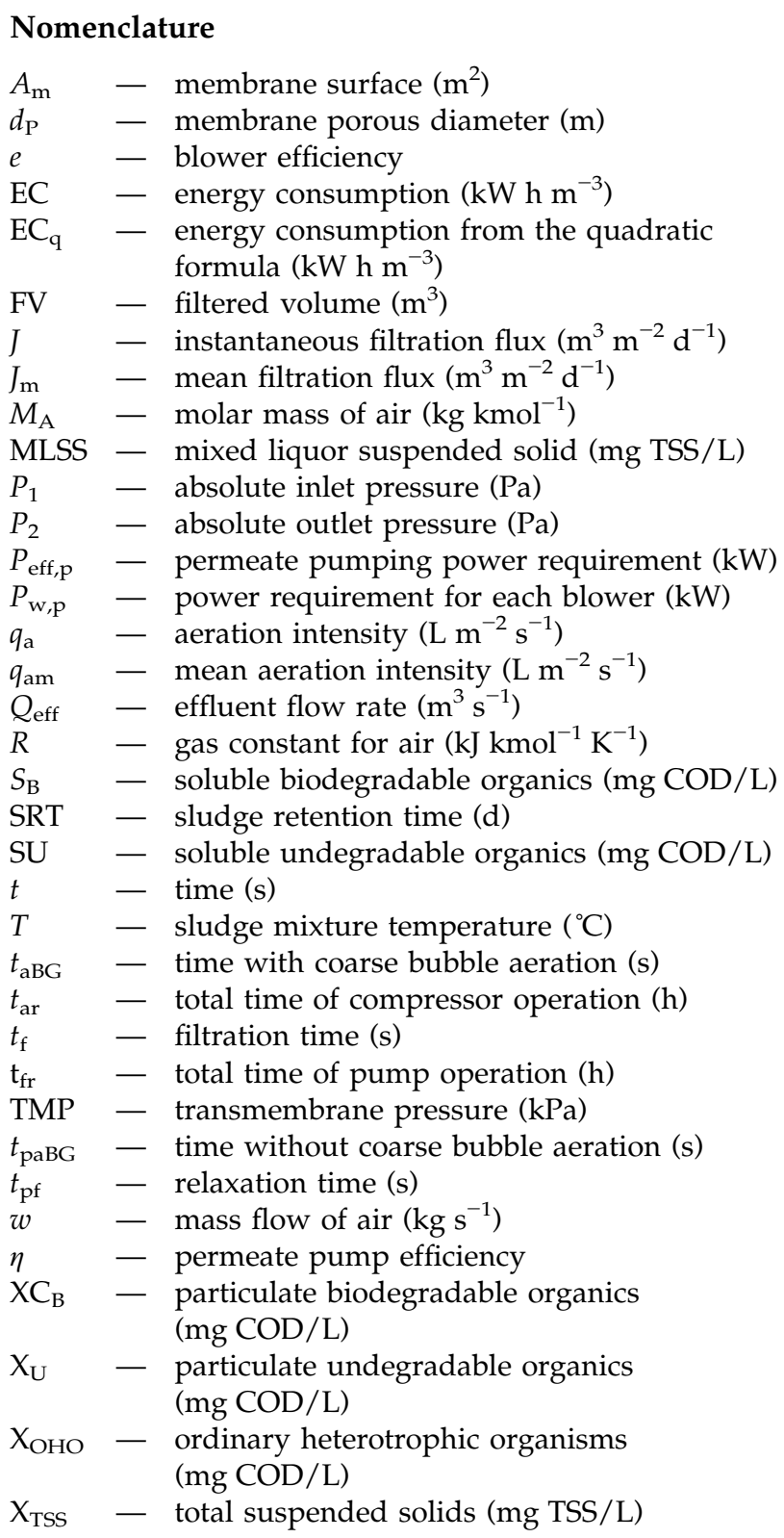

\section{References}

[1] G. Ferrero, I. Rodríguez-Roda, J. Comas, Automatic control systems for submerged membrane bioreactors: A state-of-the-art review, Water Res. 46 (2012) 3421-3433. 
[2] S. Kumar, A. Groth, L. Vlacic, An analytical index for evaluating manufacturing cost and performance of low-pressure hollow fibre membrane systems, Desalination 332 (2014) 44-51.

[3] T. Buer, J. Cumin, MBR module design and operation, Desalination 250 (2010) 1073-1077.

[4] P. Le-Clech, V. Chen, A.G. Fane, Fouling in membrane bioreactors used in wastewater treatment, J. Membr. Sci. 284 (2006) 17-53.

[5] F. Meng, S.R. Chae, A. Drews, M. Kraume, H.S. Shin, F. Yang, Recent advances in membrane bioreactors (MBRs): Membrane fouling and membrane material, Water Res. 43 (2009) 1489-1512.

[6] A. Drews, Membrane fouling in membrane bioreactors -Characterization, contradictions, cause and cures, J. Membr. Sci. 363 (2010) 1-28.

[7] G. Mannina, A. Cosenza, The fouling phenomenon in membrane bioreactors: Assessment of different strategies for energy saving, J. Membr. Sci. 444 (2013) 332-344.

[8] V. Diez, D. Ezquerra, J.L. Cabezas, A. García, C. Ramos, A modified method for evaluation of critical flux, fouling rate and in situ determination of resistance and compressibility in MBR under different fouling conditions, J. Membr. Sci. 453 (2014) 1-11.

[9] L. Böhm, A. Drews, H. Prieske, P.R. Bérubé, M. Kraume, The importance of fluid dynamics for MBR fouling mitigation, Bioresour. Technol. 122 (2012) 50-61.

[10] A. Menniti, E. Morgenroth, The influence of aeration intensity on predation and EPS production in membrane bioreactors, Water Res. 44 (2010) 2541-2553.

[11] P. Cornel, M. Wagner, S. Krause, Investigation of oxygen transfer rates in full scale membrane bioreactors, Water Sci. Technol. 47 (2003) 313-319.

[12] A.G. Zarragoitia, S. Schetrite, U.J. Jáuregui-Haza, O. Lorain, C. Albasi, Optimization of wastewater filtration process in submerged membrane bioreactors: Applicability of a dynamic model to scale up, Comput. Aided Chem. Eng. 27 (2009) 1545-1550.

[13] J.A. Gil, L. Túa, A. Rueda, B. Montaño, M. Rodríguez, D. Prats, Monitoring and analysis of the energy cost of an MBR, Desalination 250 (2010) 997-1001.

[14] A. Fenu, J. Roels, T. Wambecq, K. De Gussem, C. Thoeye, G. De Gueldre, B. Van De Steene, Energy audit of a full scale MBR system, Desalination 262 (2010), 121-128.

[15] W. Naessens, T. Maere, I. Nopens, Critical review of membrane bioreactor models-Part 1: Biokinetic and filtration models, Bioresour. Technol. 122 (2012) 95-106.

[16] T. Maere, B. Verrecht, S. Moerenhout, S. Judd, I. Nopens, BSM-MBR: A benchmark simulation model to compare control and operational strategies for membrane bioreactors, Water Res. 45 (2011) 2181-2190.

[17] C. Suh, S. Lee, J. Cho, Investigation of the effects of membrane fouling control strategies with the integrated membrane bioreactor model, J. Membr. Sci. 429 (2013) 268-281.

[18] E. Braak, M. Alliet, S. Schetrite, C. Albasi, Aeration and hydrodynamics in submerged membrane bioreactors, J. Membr. Sci. 379 (2011) 1-18.

[19] P. Schoeberl, M. Brik, M. Bertoni, R. Braun, W. Fuchs, Optimization of operational parameters for a submerged membrane bioreactor treating dyehouse wastewater, Sep. Purif. Technol. 44 (2005) 61-68.

[20] B. Verrecht, T. Maere, L. Benedetti, I. Nopens, S. Judd, Model-based energy optimisation of a small-scale decentralised membrane bioreactor for urban reuse, Water Res. 44 (2010) 4047-4056.

[21] S. Gabarrón, M. Dalmau, J. Porro, I. Rodriguez-Roda, J. Comas, Optimization of full-scale membrane bioreactors for wastewater treatment through a model-based approach, Chem. Eng. J. 267 (2015) 34-42.

[22] P. Paul, Comparing and contrasting traditional membrane bioreactor models with novel ones based on time series analysis, Membranes 3 (2013) 16-23.

[23] Y. González-Hernández, U. Jáuregui Haza, C. Albasi, M. Alliet, Development of a submerged membrane bioreactor simulator: A useful tool for teaching its functioning, Educ. Chem. Eng. 9 (2014) e32-e41.

[24] A.G. Zarragoitia, S. Schetrite, M. Alliet, U. JáureguiHaza, C. Albasi, Modelling of submerged membrane bioreactor: Conceptual study about link between activated sludge biokinetics, aeration and fouling process, J. Membr. Sci. 325 (2008) 612-624.

[25] R.L. Živorad, Design of Experiments in Chemical Engineering: A Practical Guide, Wiley-VCH, Weinheim, 2004.

[26] X.-Y. Li, X.-M. Wang, Modelling of membrane fouling in a submerged membrane bioreactor, J. Membr. Sci. 278 (2006) 151-161.

[27] S. Judd, The status of membrane bioreactor technology, Trends Biotechnol. 26 (2008) 109-116.

[28] S.J. Judd, C. Judd, Principles and Applications of Membrane Bioreactors in Water and Wastewater Treatment seconded, Elsevier, London, 2010.

[29] M.L. Davis, Water and Wastewater Engineering: Design Principles and Practice, McGraw-Hill, New York, NY, 2010.

[30] G.E.P. Box, W.G. Hunter, J. Stuart Hunter, Statistics for Experimenters: Design, Innovation and Discovery, second ed., John Wiley and Sons, New York, NY, 2005. 